\title{
The Alzheimer's Association external quality control program for cerebrospinal fluid biomarkers
}

Niklas Mattsson $^{\mathrm{a}, *}$, Ulf Andreasson ${ }^{\mathrm{a}}$, Staffan Persson ${ }^{\mathrm{a}}$, Hiroyuki Arai ${ }^{\mathrm{b}}$, Sat Dev Batish ${ }^{\mathrm{c}}$, Sergio Bernardini ${ }^{\mathrm{d}}$, Luisella Bocchio-Chiavetto ${ }^{\mathrm{e}}$, Marinus A. Blankenstein ${ }^{\mathrm{f}}$, Maria C. Carrillo ${ }^{\mathrm{g}}$, Sonia Chalbot ${ }^{\mathrm{h}}$, Els Coart ${ }^{\mathrm{i}}$, Davide Chiasserini ${ }^{\mathrm{j}}$, Neal Cutler $^{\mathrm{k}}$, Gunilla Dahlfors ${ }^{\mathrm{l}}$, Stefan Duller ${ }^{\mathrm{m}}$,

Anne M. Fagan ${ }^{\mathrm{n}}$, Orestes Forlenza ${ }^{\mathrm{o}}$, Giovanni B. Frisoni ${ }^{\mathrm{e}}$, Douglas Galasko ${ }^{\mathrm{p}}$,

Daniela Galimberti ${ }^{\mathrm{q}}$, Harald Hampel ${ }^{\mathrm{r}}$, Aase Handberg ${ }^{\mathrm{s}}$, Michael T. Heneka ${ }^{\mathrm{t}}$,

Adrianna Z. Herskovits ${ }^{\mathrm{u}}$, Sanna-Kaisa Herukka ${ }^{\mathrm{v}}$, David M. Holtzman ${ }^{\mathrm{n}}$, Christian Humpel ${ }^{\mathrm{w}}$,

Bradley T. Hyman ${ }^{\mathrm{u}}$, Khalid Iqbal ${ }^{\mathrm{h}}$, Mathias Jucker ${ }^{\mathrm{x}}$, Stephan A. Kaeser ${ }^{\mathrm{x}}$, Elmar Kaiser ${ }^{\mathrm{y}}$,

Elisabeth Kapaki ${ }^{\mathrm{z}}$, Daniel Kidd ${ }^{\mathrm{aa}}$, Peter Klivenyi ${ }^{\mathrm{bb}}$, Cindy S. Knudsen ${ }^{\mathrm{s}}$, Markus P. Kummer ${ }^{\mathrm{t}}$, James Lui ${ }^{\mathrm{cc}}$, Albert Lladódd, Piotr Lewczuk ${ }^{\mathrm{ee}}$, Qiao-Xin Lif ${ }^{\mathrm{ff}}$, Ralph Martins ${ }^{\mathrm{cc}}$, Colin Masters ${ }^{\mathrm{ff}}$, John McAuliffe ${ }^{\mathrm{c}}$, Marc Mercken ${ }^{\mathrm{gg}}$, Abhay Moghekarh ${ }^{\text {hh }}$, José Luis Molinuevo ${ }^{\mathrm{dd}}$,

Thomas J. Montine ${ }^{\mathrm{ii}}$, William Nowatzke ${ }^{\mathrm{k}}$, Richard O’Brien ${ }^{\mathrm{hh}}$, Markus Otto ${ }^{\mathrm{jj}}$,

George P. Paraskevas ${ }^{\mathrm{z}}$, Lucilla Parnetti ${ }^{\mathrm{j}}$, Ronald C. Petersen ${ }^{\mathrm{kk}}$, David Prvulovic ${ }^{\mathrm{r}}$, Herman P. M. de Reus $^{11, m m}$, Robert A. Rissman ${ }^{\mathrm{p}}$, Elio Scarpini ${ }^{\mathrm{q}}$, Alessandro Stefani ${ }^{\mathrm{nn}}$, Hilkka Soininen ${ }^{\mathrm{v}}$,

Johannes Schröder ${ }^{\mathrm{y}}$, Leslie M. Shaw ${ }^{\mathrm{oo}}$, Anders Skinningsrud ${ }^{\mathrm{pp}}$, Brith Skrogstad ${ }^{\mathrm{pp}}$, Annette Spreer ${ }^{\mathrm{qq}}$, Leda Talib ${ }^{\mathrm{o}}$, Charlotte Teunissen ${ }^{\mathrm{f}}$, John Q. Trojanowski $^{\mathrm{oo}}$, Hayrettin Tumani ${ }^{\mathrm{jj}}$, Robert M. Umek ${ }^{\text {rr }}$, Bianca Van Broeck ${ }^{\mathrm{gg}}$, Hugo Vanderstichele ${ }^{\mathrm{i}}$, Laszlo Vecsei ${ }^{\mathrm{bb}}$, Marcel M. Verbeek ${ }^{11, m m}$, Manfred Windisch ${ }^{\mathrm{m}}$, Jing Zhang ${ }^{\mathrm{ii}}$, Henrik Zetterberg ${ }^{\mathrm{a}}$, Kaj Blennow ${ }^{\mathrm{a}}$

${ }^{a}$ Clinical Neurochemistry Laboratory, Institute of Neuroscience and Physiology, Department of Psychiatry and Neurochemistry, the Sahlgrenska Academy at the University of Gothenburg, Sahlgrenska University Hospital, Mölndal, Sweden

${ }^{b}$ Department of Geriatrics and Gerontology, Institute of Development, Aging and Cancer, Tohoku University, Sendai, Japan ${ }^{c}$ Athena Diagnostics Inc., Worchester, MA, USA

${ }^{d}$ Department Biochimica Clinica, Policlinico, University of Tor Vergata, Rome, Italy ${ }^{e}$ IRCCS Centro S. Giovanni di Dio-Fatebenefratelli, Brescia, Italy

${ }^{f}$ Department of Clinical Chemistry, VU University Medical Center, Amsterdam, The Netherlands

${ }^{g}$ The Alzheimer's Association, Chicago, IL, USA

${ }^{h}$ Department of Neurochemistry, New York State Institute for Basic Research in Developmental Disabilities, Staten Island, NY, USA innogenetics, Ghent, Belgium

${ }^{j}$ Section of Neurology, Laboratory of Clinical Neurochemistry, Centre for Memory Disturbances, University of Perugia, Perugia, Italy

${ }^{k}$ Worldwide Clinical Trials, King of Prussia, PA, USA

${ }^{l}$ Department of Clinical Chemistry, Karolinska University Laboratory, Karolinska University Hospital, Stockholm, Sweden ${ }^{m} J S W$ Life Sciences GmbH, Grambach, Austria

${ }^{n}$ Department of Neurology, Alzheimer's Disease Research Center, Hope Center for Neurological Disorders, Washington University School of Medicine, St. Louis, MO, USA

${ }^{\circ}$ Laboratory of Neuroscience (LIM 27), Department and Institute of Psychiatry, Faculty of Medicine, University of Sao Paulo, Sao Paulo, Brazil

${ }^{p}$ Department of Neurosciences, UCSD School of Medicine, La Jolla, CA, USA

${ }^{q}$ Department of Neurological Sciences, University of Milan, Milan, Italy

${ }^{r}$ Department of Psychiatry, Psychosomatic Medicine and Psychotherapy, Goethe University, Frankfurt, Germany

${ }^{s}$ Department of Clinical Biochemistry, Aarhus Hospital, Aarhus University Hospital, Aarhus, Denmark

${ }^{t}$ Klinische Neurowissenschaften, Klinik und Poliklinik für Neurologie, University of Bonn, Bonn, Germany

*Corresponding author. Tel.: +46-706-393-851; Fax: +46-313-432-426.

E-mail address: niklas.mattsson@neuro.gu.se 
${ }^{u}$ MassGeneral Institute for Neurodegenerative Disease, Massachusetts General Hospital, Massachusetts Alzheimer Disease Research Center, Harvard Medical School, Charlestown, MA, USA

${ }^{v}$ Department of Neurology, University of Eastern Finland, Kuopio University Hospital, Kuopio, Finland

${ }^{w}$ Laboratory of Psychiatry and Experimental Alzheimers Research, Innsbruck Medical University, Innsbruck, Austria

${ }^{x}$ Department of Cellular Neurology, Hertie-Institute for Clinical Brain Research, University of Tübingen and DZNE-German Center for Neurodegenerative Diseases, Tübingen, Germany

${ }^{y}$ Section of Geriatric Psychiatry, University of Heidelberg, Heidelberg, Germany

${ }^{z} 1$ st Department of Neurology, Eginition Hospital, National and Kapodistrian University of Athens, Athens, Greece

aa Janssen Alzheimer Immunotherapy Research and Development, South San Francisco, CA, USA

${ }^{b b}$ Department of Neurology, University of Szeged, Szeged, Hungary

${ }^{c c}$ Centre of Excellence for Alzheimer's Disease Research and Care, School of Exercise, Biomedical and Health Sciences, Edith Cowan University, Perth, Australia

${ }^{d d}$ Alzheimer's Disease and Other Cognitive Disorders Unit, Neurology Service, Hospital Clínic, Institut d'Investigació Biomédica August Pi i Sunyer (IDIBAPS), Barcelona, Spain

${ }^{e e}$ Department of Psychiatry and Psychotherapy, Universitätsklinikum Erlangen, Erlangen, Germany

${ }^{f f}$ Neuropathology Research Group, The Mental Health Research Institute, University of Melbourne, Melbourne, Australia

${ }^{g g}$ Janssen Pharmaceutica, J\&J, Beerse, Belgium

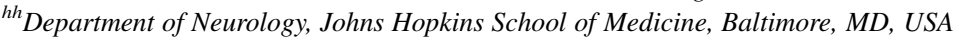

${ }^{i i}$ Department of Pathology, University of Washington, Seattle, WA, USA

${ }^{j j}$ Department of Neurology, University of Ulm, Ulm, Germany

${ }^{k k}$ Alzheimer's Disease Research Center, Mayo Clinic, Rochester, MN, USA

${ }^{l l}$ Department of Neurology, Radboud University Nijmegen Medical Centre, Donders Institute for Brain, Cognition and Behaviour, Alzheimer Centre Nijmegen, Nijmegen, The Netherlands

${ }^{m m}$ Department of Laboratory Medicine, Radboud University Nijmegen Medical Centre, Donders Institute for Brain, Cognition and Behaviour, Alzheimer Centre Nijmegen, Nijmegen, The Netherlands

${ }^{n}$ IRCCS Fondazione S. Lucia, Rome, Italy

${ }^{\circ o}$ Department of Pathology and Laboratory Medicine, University of Pennsylvania Medical Center (ADNI Biomarker Core), Philadelphia, PA, USA

${ }^{p p}$ Department of Clinical Biochemistry, Center of Laboratory Medicine, Akershus University Hospital, Oslo, Norway

${ }^{q q}$ Department of Neurology, University of Göttingen, Göttingen, Germany

${ }^{r r}$ Meso Scale Discovery, Gaithersburg, MD, USA

Abstract

Background: The cerebrospinal fluid (CSF) biomarkers amyloid $\beta$ (A $\beta$ )-42, total-tau (T-tau), and phosphorylated-tau (P-tau) demonstrate good diagnostic accuracy for Alzheimer's disease (AD). However, there are large variations in biomarker measurements between studies, and between and within laboratories. The Alzheimer's Association has initiated a global quality control program to estimate and monitor variability of measurements, quantify batch-to-batch assay variations, and identify sources of variability. In this article, we present the results from the first two rounds of the program.

Methods: The program is open for laboratories using commercially available kits for A $\beta$, T-tau, or P-tau. CSF samples (aliquots of pooled CSF) are sent for analysis several times a year from the Clinical Neurochemistry Laboratory at the Mölndal campus of the University of Gothenburg, Sweden. Each round consists of three quality control samples.

Results: Forty laboratories participated. Twenty-six used INNOTEST enzyme-linked immunosorbent assay kits, 14 used Luminex xMAP with the INNO-BIA AlzBio3 kit (both measure A $\beta-(1-42)$, P-tau(181P), and T-tau), and 5 used Meso Scale Discovery with the A $\beta$ triplex (A $\beta N-42, A \beta N-40$, and $\mathrm{A} \beta \mathrm{N}-38$ ) or T-tau kits. The total coefficients of variation between the laboratories were $13 \%$ to $36 \%$. Five laboratories analyzed the samples six times on different occasions. Within-laboratory precisions differed considerably between biomarkers within individual laboratories.

Conclusions: Measurements of CSF AD biomarkers show large between-laboratory variability, likely caused by factors related to analytical procedures and the analytical kits. Standardization of laboratory procedures and efforts by kit vendors to increase kit performance might lower variability, and will likely increase the usefulness of CSF AD biomarkers.

(C) 2011 The Alzheimer's Association. All rights reserved.

Keywords: $\quad$ Alzheimer's disease; Cerebrospinal fluid; Biomarkers; External assurance; External control; Proficiency testing

\section{Introduction}

The three major brain hallmarks in Alzheimer's disease (AD) are extracellular amyloid plaques, axonal degeneration, and intraneuronal neurofibrillary tangles, which may be monitored with the cerebrospinal fluid (CSF) biomarkers amyloid $\beta-42(\mathrm{~A} \beta-42)$, total-tau (T-tau), and phosphorylated-tau (P-tau), respectively [1-4]. These three biomarkers have high diagnostic accuracy for established 
$\mathrm{AD}$ [5]. They may also be used to identify AD before onset of dementia at the stage of mild cognitive impairment, as shown in both single-center [6-8] and large-scale heterogeneous multicenter studies [9-11], and to predict mild cognitive impairment/AD in those who are cognitively normal [12,13]. However, measured biomarker levels differ greatly between studies (Supplementary Fig. 1 and Supplementary Table 1), and the reported diagnostic accuracy of the biomarkers varies significantly $[14,15]$. These variations could be the result of preanalytical, analytical, or manufacturing processes that affect assay-related factors [16]. Preanalytical factors include selection of study participants, procedures of lumbar puncture, sample handling, and sample storage [16-20]. Possible analytical factors include various differences in laboratory procedures among centers and technicians [21]. Assay-related factors (between-lot) arise from manufacturing variations in the source material for components and reagents in the analytical kits and random variability of the production process. These issues are summarized in Table 1.

\subsection{Interlaboratory variations}

There are several commercially available assays for the determination of CSF A $\beta-42$, T-tau, and P-tau. Most laboratories in the program used the INNOTEST enzyme-linked immunosorbent assays (ELISAs) or the bead-based Luminex xMAP platform with the INNO-BIA AlzBio3 (both Innogenetics, Ghent, Belgium, www.innogenetics.com), which quantifies $A \beta(1-42)$ (called $A \beta-42$ later in text), T-tau, and P-tau(181P) (called P-tau later in the text). Meso Scale Discovery (MSD, Gaithersburg, MD, www.mesoscale.com) technology was used by some laboratories for CSF A $\beta \mathrm{N}$ $42, \mathrm{~A} \beta \mathrm{N}-40, \mathrm{~A} \beta \mathrm{N}-38$, and T-tau measurements. Although the observed biomarker concentrations may vary significantly between platforms, these techniques seem to have similar diagnostic accuracy for patients with $\mathrm{AD}$ versus controls [22]. The within-center coefficients of variation (CV) are low, generally within $10 \%$ to $15 \%$, and the intra-assay CVs are generally within $5 \%$ to $10 \%[18,22-25]$. However, two control surveys of CSF A $\beta-42$, T-tau, and P-tau reported interassay and interlaboratory CVs of approximately $20 \%$ to $35 \%[25,26]$. These values are in agreement with the variability seen in the largest published multicenter trial of early-stage $\mathrm{AD}$ so far, which included measurements performed at several laboratories [9].

\subsection{Introducing a new global quality control program}

Novel biomarker measurements may initially present significant intercenter differences before quality control (QC) programs have been established. To facilitate the worldwide use of CSF biomarkers in clinical dementia investigations and in research, it was decided at the International Conference on Alzheimer's Disease (2009) in Vienna to initiate an international QC program for AD CSF biomarkers. The
Table 1

Possible sources of variability between CSF studies

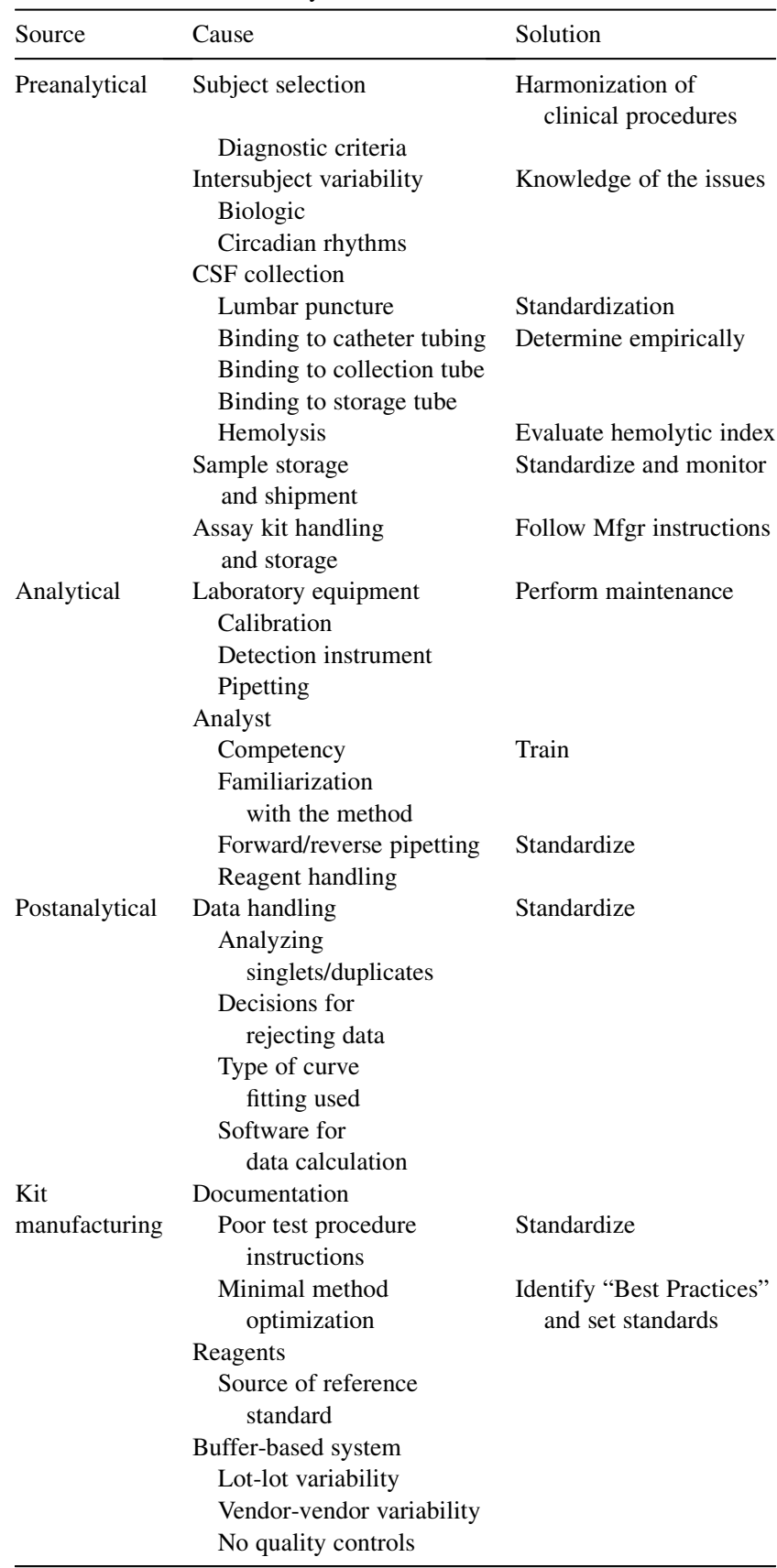

Abbreviations: CSF, cerebrospinal fluid; Mfgr, manufacturer.

program is run by the Alzheimer's Association and administrated from the Clinical Neurochemistry Laboratory at the Mölndal campus of the University of Gothenburg, Sweden. The program consists of (1) a standardized operating procedure (SOP) for lumbar puncture and CSF sample handling procedures [5], and (2) an external comparison program of CSF analyses between laboratories. The program is open for any laboratory using a commercially available assay for CSF A $\beta$, T-tau, or P-tau. In-house assays and assays for which samples must be sent to kit vendors (e.g., P-tau231) 
are not part of the program. The results of the first two rounds of the program, which were completed during the spring of 2010, are presented in this report.

\section{Materials and methods}

\subsection{CSF samples}

CSF pools were constructed in Mölndal, Sweden, from a large number of fresh, de-identified samples from the clinical routine workflow. All samples tested negative for human immunodeficiency virus and hepatitis B and C. Samples with suspected Creutzfeldt-Jakob disease were excluded. The pools were prepared by experienced and certified laboratory technicians. The pools were thoroughly mixed and underwent one freeze-thaw cycle before aliquotation in $500-\mu \mathrm{L}$ portions in polypropylene screw-cap tubes (Sarstedt Art. No. 72.692, $1.5 \mathrm{~mL}$, Sarstedt AG \& Co., Nümbrecht, Germany), were frozen at $-80^{\circ} \mathrm{C}$, and were distributed to the participating laboratories on dry ice by courier. All laboratories verified that the samples had arrived frozen. In total, the laboratories received six blinded QC samples, including one sample each from the pools 2009-1A and 2009-1B for the first round, and one sample each from the pools 2010$2 \mathrm{~A}$ and 2010-2B for the second round. For each round, the laboratories also received one aliquot from the pool QC-L, which will be the same in the coming years, to evaluate longitudinal stability. The blinded challenge samples differed in their AD biomarker profiles. Samples 2009-1A, 2010-2A, and QC-L had levels of A $\beta-42$, T-tau, and Ptau essentially in the range for healthy subjects. Sample 2009-1B had a classical AD biomarker profile, with low A $\beta-42$ and high T-tau and P-tau. Sample 2010-2B had essentially normal levels of $A \beta-42$, combined with high T-tau and P-tau.

\subsection{CSF analysis}

Laboratories used assay lots that were available in their laboratories. Samples were analyzed in duplicate as part of the laboratories' ordinary activities. Five laboratories routinely processing a large number of samples assessed within-laboratory precision performance by analyzing the samples six times using different plates. These laboratories (Amsterdam, Mölndal, Erlangen, Ghent, and Pennsylvania) are called reference laboratories later in the text. All results were reported back to Mölndal for data analysis.

\subsection{Data analysis}

\subsubsection{General statistics}

Biomarker results were statistically analyzed and grouped by rounds, samples, and analytical techniques. Mean levels, standard deviations, and total CVs were calculated. For the reference laboratories, within-laboratory CVs were calculated. Correlations were assessed using Pearson correlation coefficient. GraphPad Prism 5 (GraphPad Software, La Jolla, CA, USA) was used for these analyses.

\subsubsection{Variance component analysis}

Analysis of variance was performed with the mixed procedure of SAS software version 9.2 (SAS Institute Inc., Cary, NC, USA) using Restricted Maximum Likelihood estimation of covariances. Analyses were performed in-line with International Organization for Standardization (ISO) standard ISO5725 and National Committee for Clinical Laboratory Standards (NCCLS) guideline Evaluation Of Precision Performance Of Quantitative Measurement Methods (EP5-A2). The estimated variance components were within-laboratory, between-laboratory, and between-lot variability. Following a widely accepted statistical convention, negative variance estimates were set to 0 .

\section{Results}

\subsection{Participants and analytical techniques}

Forty laboratories participated (Supplementary Table 2). Two laboratories participated only in the first round, and three laboratories participated only in the second round. The laboratories used INNOTEST ELISAs $(\mathrm{n}=26)$, Luminex xMAP with the INNO-BIA AlzBio3 kit $(\mathrm{n}=14)$, and MSD with the $A \beta$ triplex kit ( $n=4$ in the first round, $n=$ 5 in the second round) or T-tau kit (MSD) $(n=1)$. A $\beta$ triplex may be used with different $A \beta$ detection antibodies. The 4G8 antibody binds to $A \beta$ amino acid residues $18-22$, and the $6 \mathrm{E} 10$ antibody binds to residues $3-8$. Both these antibodies were used by laboratories in the program. Every sample volume was enough for duplicate analyses with ELISA (T-tau: $2 \times 25 \mu \mathrm{L}, \mathrm{A} \beta-42: 2 \times 25 \mu \mathrm{L}$, and P-tau: $2 \times 25$ $\mu \mathrm{L})$, xMAP $(2 \times 75 \mu \mathrm{L})$, and MSD $(\mathrm{A} \beta$ triplex: $2 \times 25$ $\mu \mathrm{L}$ and T-tau: $2 \times 25 \mu \mathrm{L}$ ), or combinations of these. Several laboratories used multiple techniques.

\subsection{Total variability}

Results were grouped according to analytical techniques and samples. The total CVs among centers were $16 \%$ to $28 \%$ for ELISA (Fig. 1 A-C), $13 \%$ to $36 \%$ for xMAP (Fig. 1 DF), and $16 \%$ to $36 \%$ for MSD (Fig. 1 G-I). CVs for MSD must be interpreted with caution, because they include both the 4G8 and 6E10 assays, and the 6E10 and the 4G8 antibodies bind to different epitopes on the $\mathrm{A} \beta$ peptide. Note that, given the study design of one reported mean value per sample and laboratory, this total variability includes both within- and between-center variability.

\subsection{Correlations between $A$ and $B$ samples}

For each round and analyte, correlations between results for the A and B samples were analyzed for ELISA, xMAP, and MSD (Supplementary Fig. 2). In the ideal 

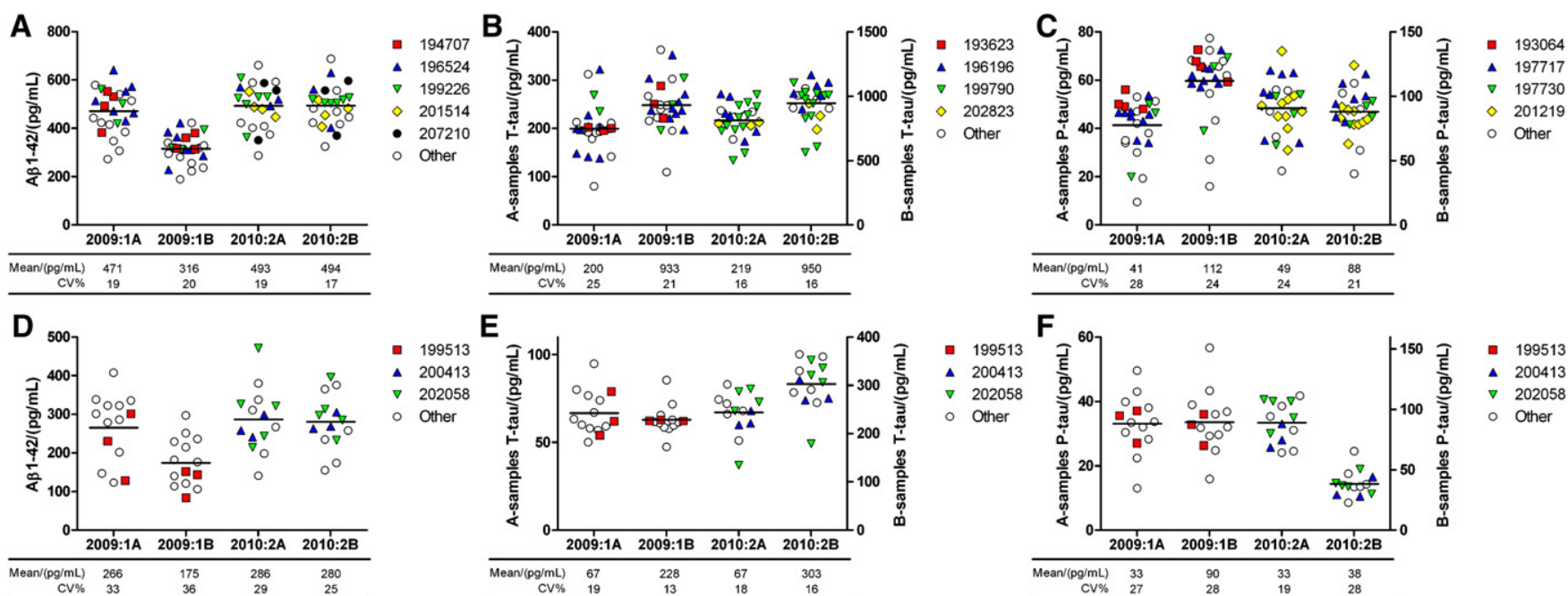

E
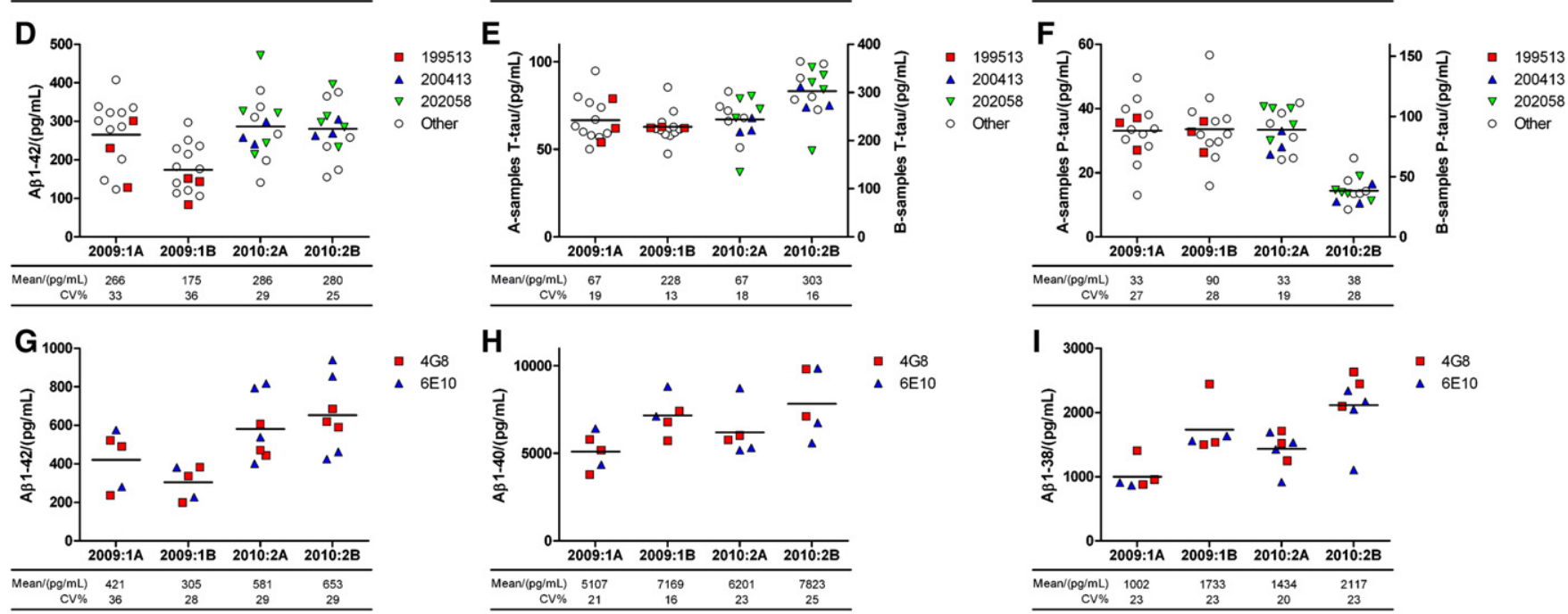

Fig. 1. Results for enzyme-linked immunosorbent assay (ELISA; A-C), xMAP (D-F), and Meso Scale Discovery (G-I) from rounds 1 (1A and 1B) and 2 (2A and 2B). Panels B, C, E, and F have secondary y-axes owing to large differences between samples. Different symbols indicate different kit batches for ELISA and xMAP, and different assays for Meso Scale Discovery (6E10, blue triangle; 4G8, red square).

situation, the measured concentration range is small, and the correlation is then of secondary interest. However, when the range is wide, as in the present results, a high correlation indicates differences between laboratories but consistency within laboratories, whereas a low correlation may indicate inconsistency within laboratories combined with other variation.

\subsection{Within-laboratory precision}

Within-laboratory $\mathrm{CV}$ s were examined at the reference laboratories for ELISA and xMAP in the first (Figs. 2 and 3 ) and the second round (Figs. 4 and 5). CVs were $3.2 \%$ to $24 \%$ for ELISA and $2.3 \%$ to $26 \%$ for xMAP, but differed between analytes within individual laboratories, indicating assay-dependent variations. For example, in xMAP runs for sample 2009-1A, reference laboratory 5 had low variations for $\mathrm{A} \beta-42$ and $\mathrm{T}$-tau but high variation for P-tau (Fig. 3 A-C). For the same analyte and platform, important differences in within-center variability could be noticed among reference laboratories. Most striking are the consistently low $\mathrm{CVs}$ for $\mathrm{A} \beta-42$ measured with xMAP by reference laboratory 5 . Also, a platform-dependent variation was observed with larger differences in mean levels between laboratories for the xMAP format as compared with ELISA.

\subsection{Longitudinal evaluation}

The QC-L sample was analyzed in both rounds. Mean levels and total CVs among the laboratories are presented in Supplementary Fig. 3. There were no major changes in total CVs over time, except a decrease in variation for T-tau measured by ELISA. We also calculated within-laboratory $\mathrm{CV}$ s between the two rounds. For ELISA, the means of these between-round $\mathrm{CV}$ s were $14 \%, 10 \%$, and $11 \%$ for $\mathrm{A} \beta-42$, Ttau, and P-tau, respectively. For xMAP, the means were $14 \%$, $9 \%$, and $11 \%$, respectively.

\subsection{Differences in absolute values}

The analytical techniques reported different absolute values for the biomarkers. ELISA values were higher than xMAP values, especially for $A \beta-42$ and T-tau. MSD values for $A \beta$ 42 were intermediate to ELISA and XMAP in the first round and higher than ELISA values in the second round (Fig. 1).

\subsection{Contributions of between-laboratory, within-} laboratory, and between-lot variability to the total variability

Contributions of between-laboratory, within-laboratory, and between-lot variability to the total variability were 

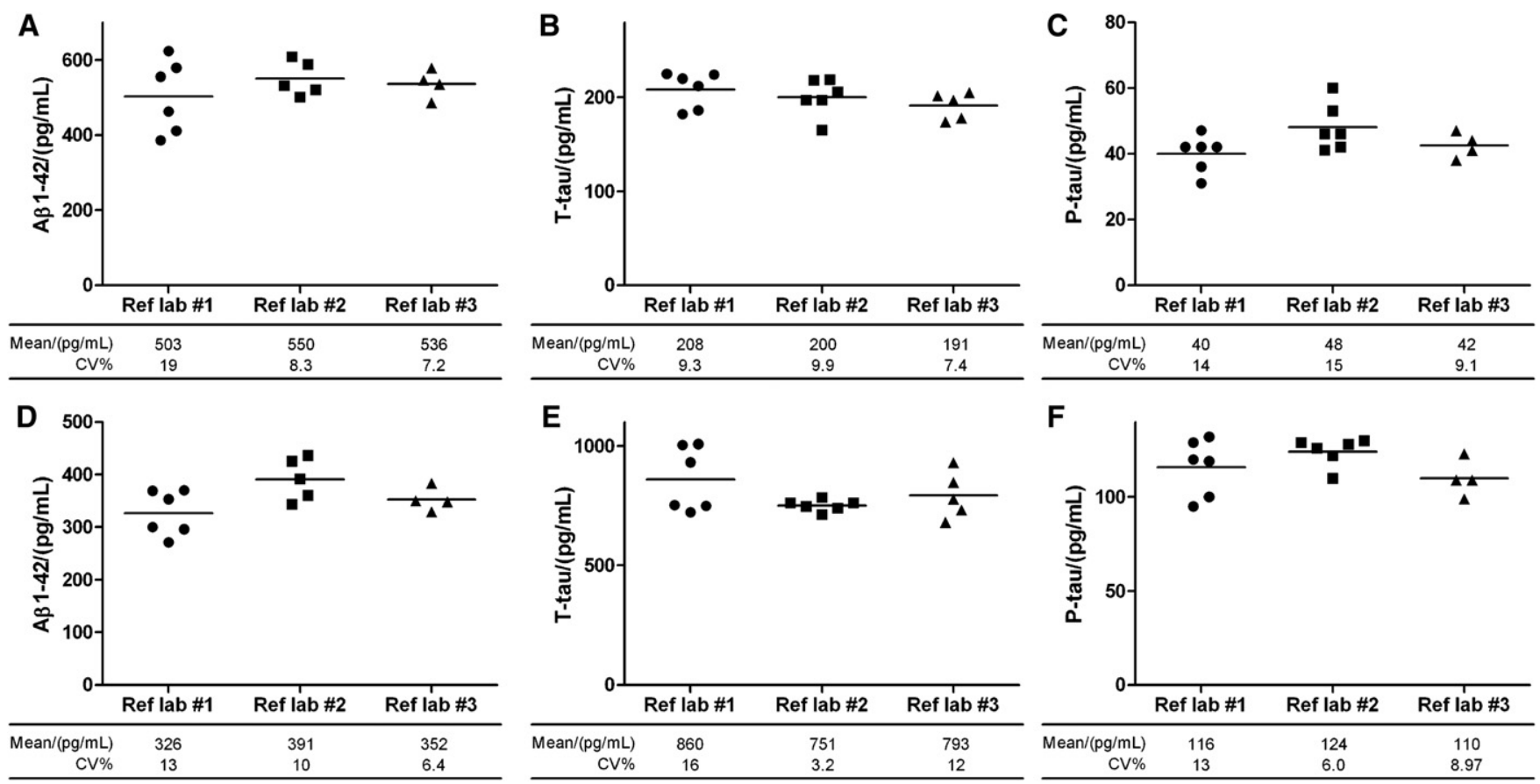

Fig. 2. ELISA results from the reference laboratories from the first round. Results for sample 2009-1A are shown in panels A-C, and results for sample 2009-1B are shown in panels D-F.

estimated using variance component analysis for ELISA and Luminex measurements. Samples from lots that were used in a minimum of 10 repeats were included. Estimates for the within-laboratory components were based only on data pertaining to the QC-L sample that were repeated in round 1 and round 2. Because of the unbalanced design and limited information per assay lot, variance components were estimated with large uncertainties. Therefore, we decided to limit interpretation of analysis of variance to the rankings of the different factors in contribution to overall variability. The rankings of the contributing factors differed among techniques and analytes (Supplementary Table 3).

\section{Discussion}

This is the first data report from the Alzheimer's Association QC program for AD CSF biomarkers. The total CVs between laboratories ranged from $13 \%$ to $36 \%$, which is comparable with what has been seen in earlier smaller investigations $[25,26]$. No major differences in CVs were seen between the two rounds, which was as expected because there were no active interventions between the rounds. As the QC program continues, the most likely causes for the variations can be identified and addressed. For example, if a laboratory consistently reports low-rank data, the divergence is probably because of analytical factors. Moreover, oscillations between low- and high-rank results suggest that the origin of the inconsistency may be either analytical or assay-related factors, or a combination of both. Wellestablished routine CSF parameters, such as albumin and immunoglobulin levels, often have between-laboratory CVs of less than $10 \%$ to $15 \%$ in external control assurance programs. Biomarker scientists and manufacturers should strive to achieve this level of reproducibility for CSF AD markers. Such a goal is already within reach for some of the markers.

\subsection{What causes the variability?}

The key question is what causes the total variability described. Because pooled QC samples prepared in bulk at a single site were used in this study, preanalytical confounding factors related to the sample preparation were eliminated. Detected variations must have been caused by differences in other preanalytical procedures (e.g., handling/storage of QC samples or commercial kits at individual sites), analytical procedures, or variations related to the commercial assays themselves. With only two program rounds analyzed and many different assay lots used, the estimates of the contributions from between-laboratory, within-laboratory, and between-lot components to the total variability could only be interpreted as rankings instead of quantitative CVs. In general, different kit batches were rather evenly spread among the reported results, indicating that the total variations were not mainly caused by batch-to-batch variability. Intrabatch variability will contribute to the observed variations but cannot be singled out in this study. It may be noted that variations between laboratories were less for the reference laboratories than for all participating laboratories. Because the reference laboratories routinely process large 

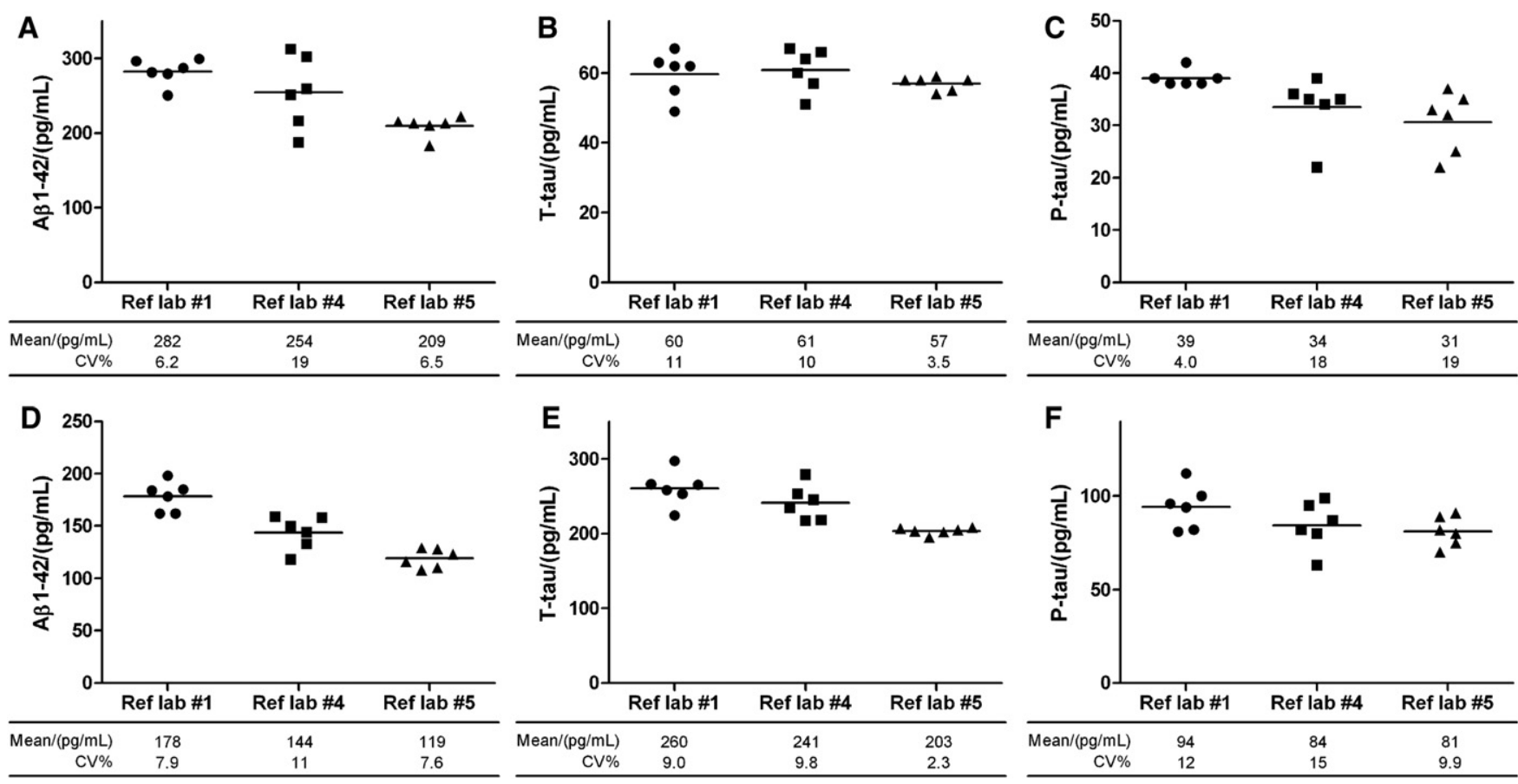

Fig. 3. xMAP results from the reference laboratories from the first round. Results for sample 2009-1A are shown in panels A-C, and results for sample 2009-1B are shown in panels D-F. Data points missing in panels B and E are because of experimental error related to high background in the tau assay.

amounts of samples, this highlights the importance of experience to decrease variations.

Differences in within-laboratory CVs among the biomarkers within individual reference laboratories suggest that assay-related factors are important. For example, for the xMAP analyses of sample 2009-1A, reference laboratory 1 had low CV for P-tau and high for $A \beta-42$ and T-tau, whereas reference laboratory 5 had high $\mathrm{CV}$ for P-tau and low for A $\beta-42$ and T-tau (Fig. 3 A-C). Because all analytes are measured simultaneously with the XMAP system, such
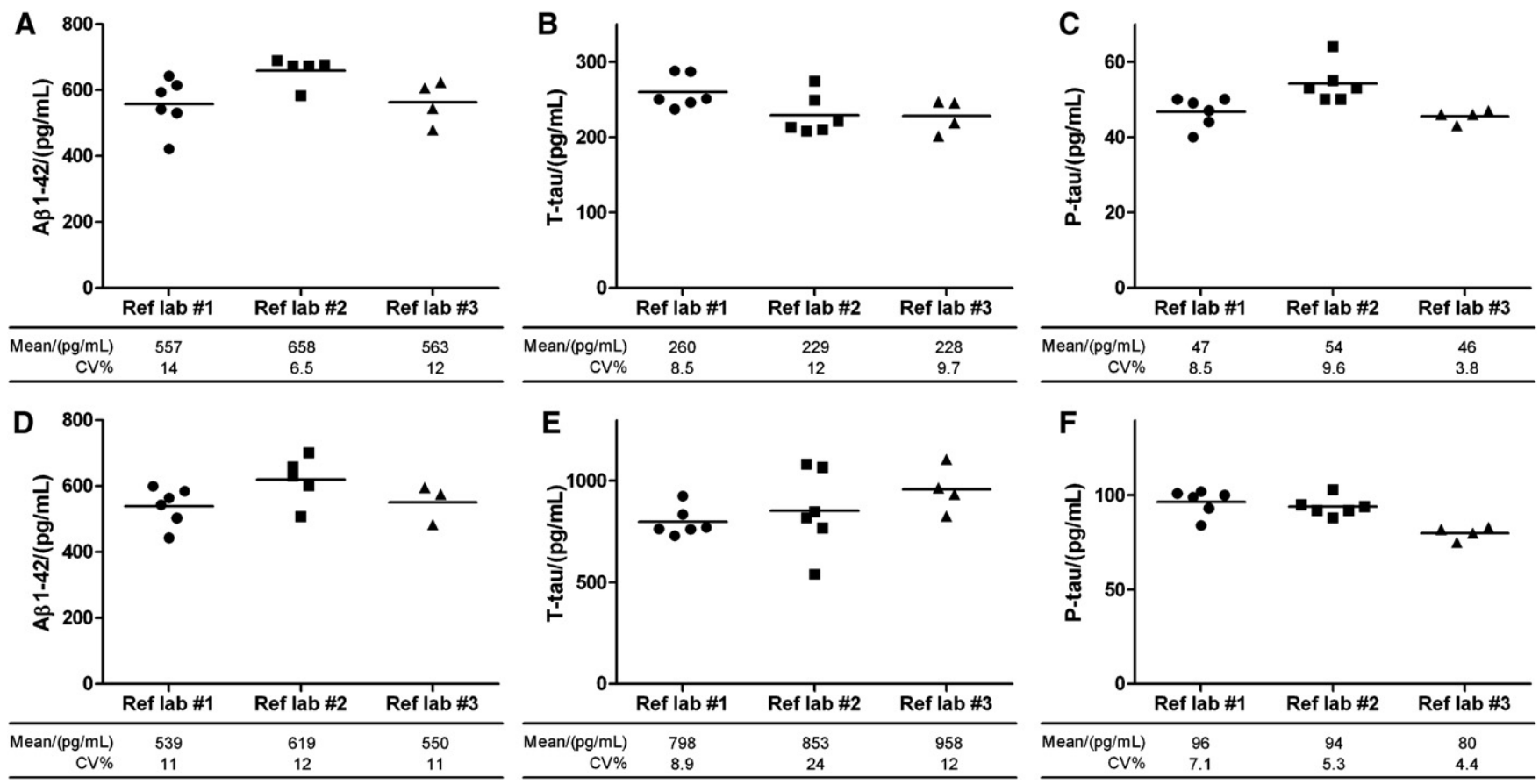

Fig. 4. ELISA results from the reference laboratories from the second round. Results for sample 2010-2A are shown in panels A-C, and results for sample 2010$2 \mathrm{~B}$ are shown in panels D-F. 

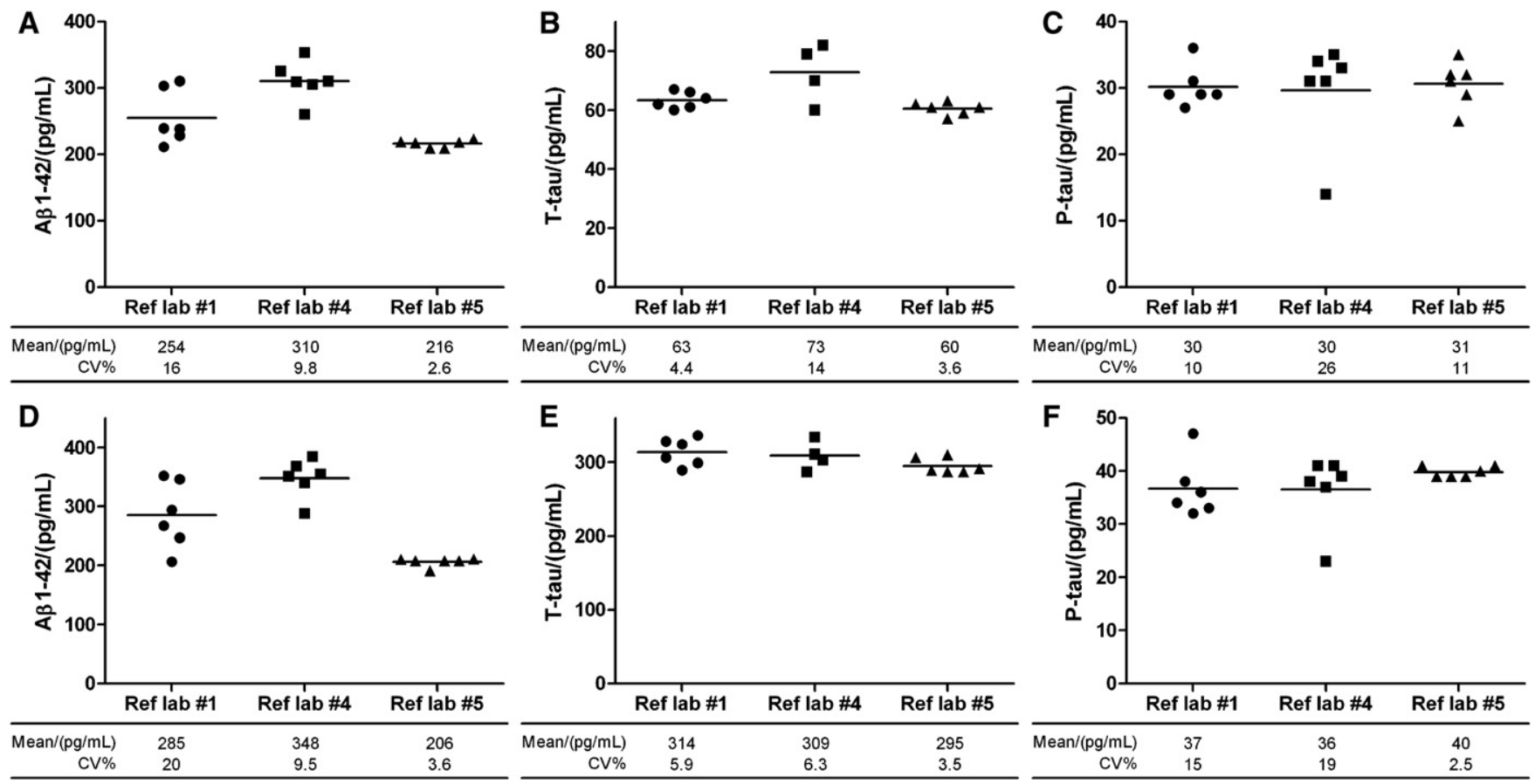

Fig. 5. xMAP results from the reference laboratories from the second round. Results for sample 2010-2A are shown in panels A-C, and results for sample 2010$2 \mathrm{~B}$ are shown in panels D-F.

discrepancies are difficult to explain by variations in laboratory procedures and more likely caused by variations inherent to the kit itself. However, it cannot be ruled out that individual analytes in a multiplexed assay might be more or less sensitive to certain laboratory procedures. Possible assay-related factors are variations in antibody purification, coating of plates and beads, and preparation and stability of standards. Such sources of variation need to be decreased to a minimum, which requires increased efforts by kit manufacturers. The ideal approach is a collaborative effort between commercial kit vendors, instrument platform manufacturers, reference standardization programs, and laboratories using these methods.

\subsection{Lack of certified reference materials}

Mean levels of biomarkers differ between the analytical techniques ELISA, xMAP, and MSD. This is ultimately caused by the lack of certified reference materials (CRMs) and calibrators for CSF A $\beta-42$, T-tau, and P-tau. CRMs (also called standard reference materials) are developed by metrology institutes, such as the United States Pharmacopeia and the National Institute of Standards and Technology (NIST) in the United States, and the International Federation of Clinical Chemistry and Laboratory Medicine (IFCC), World Health Organization, and the National Institute for Biological Standards and Control [27]. The reference materials include primary CRMs, produced with a certified value of purity, and secondary CRMs, which often are samples of human body fluids evaluated against primary CRMs. It is relatively easy to determine the purity of small molecules, such as glucose or cholesterol, which allow measurements in SI units in a defined matrix (e.g., serum or CSF). However, it is more difficult to establish the purity of proteins because of heterogeneities caused by post-translational modifications or contaminations. This makes it difficult to reach full SI traceability for proteins, and standardization is sometimes done with "artifact standards," traced to the World Health Organization reference preparations, reporting concentrations in International Units (IUs) instead of SI units. One recent example of the complexity of establishing a protein CRM is the development of the troponin standard SRM 2921 (human cardiac troponin complex) [28]. The development of CRMs for CSF AD biomarkers would be a major challenge for the AD biomarker community. Such a complicated task would require devotion and orchestrated efforts by researchers, industry, and metrology institutes. If successful, it would allow full global traceability and comparability of biomarker results, also among analytical techniques and centers.

\subsection{Standardization among clinical studies}

The QC program was recently extended with a standardization program for clinical studies, called University of Gothenburg CSF 2010 (UGOT CSF 2010). For this, a CSF pool of $2000 \mathrm{~mL}$ was constructed and aliquoted in $500-\mu \mathrm{L}$ portions. Multiple aliquots have been analyzed in Gothenburg to determine biomarker concentrations with high precision in this center. These aliquots may be requested by contacting the QC program coordinator at neurochem@ neuro.gu.se. When including UGOT CSF 2010 biomarker 
measurements in publications, researchers enable normalization of their data or comparison with other studies. Authors may, for example, report their measured concentrations in their publications and conclude that "The UGOT CSF 2010 samples were within mean \pm 2 SD for $A \beta-42$, Ttau and P-tau."

\subsection{Future prospects and conclusions}

The QC program will continue with multiple test rounds each year. The program is still open for enrollment, and inquiries regarding participation can be made to the coordinator at neurochem@neuro.gu.se. The next rounds will include checklists for each analytical technique, in an attempt to identify analytical factors differing between laboratories. These checklists include information on instrument calibration, use of manual or automated techniques, sample handling and storage, handling of assay reagents and calibrators, use of internal control samples, assay conditions during preincubation and incubation, settings for data analysis, and criteria for run acceptance (for more information and checklists, see the program homepage http:// neurochem.gu.se/TheAlzAssQCProgram). The aim is that this information will serve as a basis to identify factors that influence within- and between-laboratory variations. The participating laboratories may use the summary data to alter their procedures to harmonize their measurements. The QC program can be used to monitor the progress of these efforts.

This initiative should be viewed in the larger context of the development of SOPs for the measurement of diagnostic markers for the early detection of AD. This is needed for all biomarker modalities, including biochemical markers, magnetic resonance imaging markers, and positron emission tomography imaging markers using fluorodeoxyglucose or amyloid ligands [29]. An effort similar to the QC program described in this article is the development of SOPs for magnetic resonance imaging measurements of hippocampal atrophy, which is being carried out by an international workgroup [30]. The development of SOPs for biochemical and imaging markers will be a mandatory step for the introduction of new revised diagnostic criteria for AD that include biomarker information.

It should be noted that the data presented in this article do not hinder the implementation of CSF biomarkers for research or clinical use, but they highlight the present difficulties in establishing universal cutoff levels for the biomarkers. The variations put great demands on each laboratory to develop routines to ensure longitudinal stability in the values they report, for example, by testing multiple incoming kit lots and selecting the ones that best reproduce values in internal controls. Each laboratory must develop their own reference limits or check their method agreements against laboratories who have published such data. These efforts will increase the availability of AD CSF biomarkers as tools for researchers and clinicians.

\section{Acknowledgments}

The authors thank Åsa Källén, Monica Christiansson, Sara Hullberg, and Dzemila Secic for excellent technical assistance.

K.B., H.Z., N.M., and U.A. designed the study. N.M. and U.A. performed general statistical analyses, and E.C. performed the variance component analysis. N.M. drafted the manuscript. S.P. was the study coordinator. All authors participated in interpretation of data, revised the manuscript for intellectual content, and approved the final version.

A generous grant from the Alzheimer's Association supported this study.

\section{References}

[1] Strozyk D, Blennow K, White LR, Launer LJ. CSF Abeta 42 levels correlate with amyloid-neuropathology in a population-based autopsy study. Neurology 2003;60:652-6.

[2] Tapiola T, Alafuzoff I, Herukka SK, Parkkinen L, Hartikainen P, Soininen H, et al. Cerebrospinal fluid \{beta\}-amyloid 42 and tau proteins as biomarkers of Alzheimer-type pathologic changes in the brain. Arch Neurol 2009;66:382-9.

[3] Fagan AM, Mintun MA, Mach RH, Lee SY, Dence CS, Shah AR, et al. Inverse relation between in vivo amyloid imaging load and cerebrospinal fluid Abeta42 in humans. Ann Neurol 2006;59:512-9.

[4] Forsberg A, Engler H, Almkvist O, Blomquist G, Hagman G, Wall A, et al. PET imaging of amyloid deposition in patients with mild cognitive impairment. Neurobiol Aging 2008;29:1456-65.

[5] Blennow K, Hampel H, Weiner M, Zetterberg H. Cerebrospinal fluid and plasma biomarkers in Alzheimer disease. Nat Rev Neurol 2010; 6:131-44.

[6] Zetterberg H, Wahlund LO, Blennow K. Cerebrospinal fluid markers for prediction of Alzheimer's disease. Neurosci Lett 2003;352:67-9.

[7] Herukka SK, Hallikainen M, Soininen H, Pirttila T. CSF Abeta42 and tau or phosphorylated tau and prediction of progressive mild cognitive impairment. Neurology 2005;64:1294-7.

[8] Hansson O, Zetterberg H, Buchhave P, Londos E, Blennow K, Minthon L. Association between CSF biomarkers and incipient Alzheimer's disease in patients with mild cognitive impairment: a follow-up study. Lancet Neurol 2006;5:228-34.

[9] Mattsson N, Zetterberg H, Hansson O, Andreasen N, Parnetti L, Jonsson M, et al. CSF biomarkers and incipient Alzheimer disease in patients with mild cognitive impairment. JAMA 2009;302:385-93.

[10] Visser PJ, Verhey F, Knol DL, Scheltens P, Wahlund LO, FreundLevi Y, et al. Prevalence and prognostic value of CSF markers of Alzheimer's disease pathology in patients with subjective cognitive impairment or mild cognitive impairment in the DESCRIPA study: a prospective cohort study. Lancet Neurol 2009;8:619-27.

[11] Shaw LM, Vanderstichele H, Knapik-Czajka M, Clark CM, Aisen PS, Petersen RC, et al. Cerebrospinal fluid biomarker signature in Alzheimer's disease neuroimaging initiative subjects. Ann Neurol 2009; 65:403-13.

[12] Fagan AM, Roe CM, Xiong C, Mintun MA, Morris JC, Holtzman DM. Cerebrospinal fluid tau/beta-amyloid(42) ratio as a prediction of $\operatorname{cog}$ nitive decline in nondemented older adults. Arch Neurol 2007; 64:343-9.

[13] Li G, Sokal I, Quinn JF, Leverenz JB, Brodey M, Schellenberg GD, et al. CSF tau/Abeta42 ratio for increased risk of mild cognitive impairment: a follow-up study. Neurology 2007;69:631-9.

[14] Blennow K, Hampel H. CSF markers for incipient Alzheimer's disease. Lancet Neurol 2003;2:605-13.

[15] Sunderland T, Linker G, Mirza N, Putnam KT, Friedman DL, Kimmel LH, et al. Decreased beta-amyloid1-42 and increased tau 
levels in cerebrospinal fluid of patients with Alzheimer disease. JAMA 2003;289:2094-103.

[16] Bjerke M, Portelius E, Minthon L, Wallin A, Anckarsäter H, Anckarsäter R, et al. Confounding factors influencing amyloid beta concentration in cerebrospinal fluid. Int J Alzheimers Dis 2010 (in press).

[17] Lewczuk P, Beck G, Esselmann H, Bruckmoser R, Zimmermann R, Fiszer M, et al. Effect of sample collection tubes on cerebrospinal fluid concentrations of tau proteins and amyloid beta peptides. Clin Chem 2006;52:332-4.

[18] Andreasen N, Hesse C, Davidsson P, Minthon L, Wallin A, Winblad B, et al. Cerebrospinal fluid beta-amyloid(1-42) in Alzheimer disease: differences between early- and late-onset Alzheimer disease and stability during the course of disease. Arch Neurol 1999;56:673-80.

[19] Schoonenboom NS, Mulder C, Vanderstichele H, Van Elk EJ, Kok A, Van Kamp GJ, et al. Effects of processing and storage conditions on amyloid beta (1-42) and tau concentrations in cerebrospinal fluid: implications for use in clinical practice. Clin Chem 2005; 51:189-95.

[20] Bibl M, Esselmann H, Otto M, Lewczuk P, Cepek L, Ruther E, et al. Cerebrospinal fluid amyloid beta peptide patterns in Alzheimer's disease patients and nondemented controls depend on sample pretreatment: indication of carrier-mediated epitope masking of amyloid beta peptides. Electrophoresis 2004;25:2912-8.

[21] Teunissen CE, Verwey NA, Kester MI, van Uffelen K, Blankenstein MA. Standardization of assay procedures for analysis of the CSF biomarkers amyloid beta((1-42)), tau, and phosphorylated tau in Alzheimer's disease: report of an International Workshop. Int J Alzheimers Dis (in press)
[22] Olsson A, Vanderstichele H, Andreasen N, De Meyer G, Wallin A, Holmberg B, et al. Simultaneous measurement of beta-amyloid(142), total tau, and phosphorylated tau (Thr181) in cerebrospinal fluid by the xMAP technology. Clin Chem 2005;51:336-45.

[23] Reijn TS, Rikkert MO, van Geel WJ, de Jong D, Verbeek MM. Diagnostic accuracy of ELISA and xMAP technology for analysis of amyloid beta(42) and tau proteins. Clin Chem 2007;53:859-65.

[24] Andreasen N, Vanmechelen E, Vanderstichele H, Davidsson P, Blennow K. Cerebrospinal fluid levels of total-tau, phospho-tau and A beta 42 predicts development of Alzheimer's disease in patients with mild cognitive impairment. Acta Neurol Scand Suppl 2003; 179:47-51.

[25] Lewczuk P, Beck G, Ganslandt O, Esselmann H, Deisenhammer F, Regeniter A, et al. International quality control survey of neurochemical dementia diagnostics. Neurosci Lett 2006;409:1-4.

[26] Verwey NA, van der Flier WM, Blennow K, Clark C, Sokolow S, De Deyn PP, et al. A worldwide multicentre comparison of assays for cerebrospinal fluid biomarkers in Alzheimer's disease. Ann Clin Biochem 2009;46:235-40.

[27] Bunk DM. Reference materials and reference measurement procedures: an overview from a national metrology institute. Clin Biochem Rev 2007;28:131-7.

[28] Bunk DM, Welch MJ. Characterization of a new certified reference material for human cardiac troponin I. Clin Chem 2006;52:212-9.

[29] Blennow K. Biomarkers for Alzheimer's disease. Nat Med (in press)

[30] Frisoni G, Jack CR. Harmonization of MR-based manual hippocampal segmentation: a mandatory step for wide clinical use. Alzheimers Dement 2010 (in press) 
Supplementary Table 1

References for Fig. 1

\begin{tabular}{ll}
\hline 1 & \\
2 & (Brew, Pemberton et al. 2005) \\
3 & (Wallin, Blennow et al. 2006) \\
4 & (Jia, Meng et al. 2005) \\
5 & (Rosso, van Herpen et al. 2003) \\
6 & (Kanemaru, Kameda et al. 2000) \\
7 & (Pijnenburg, Schoonenboom et al. 2004) \\
8 & (Schoonenboom, Pijnenburg et al. 2004) \\
9 & (Ivanoiu and Sindic 2005) \\
10 & (Rosler, Wichart et al. 2001) \\
11 & (Olsson, Hoglund et al. 2003) \\
12 & (Noguchi, Yoshita et al. 2005) \\
13 & (Gomez-Tortosa, Gonzalo et al. 2003) \\
14 & (Otto, Esselmann et al. 2000) \\
15 & (Kapaki, Paraskevas et al. 2003) \\
16 & (Kapaki, Kilidireas et al. 2001) \\
17 & (Sjogren, Minthon et al. 2000) \\
18 & (Mollenhauer, Cepek et al. 2005) \\
19 & (Sjogren, Davidsson et al. 2001) \\
20 & (Riemenschneider, Wagenpfeil et al. 2002) \\
21 & (Stefani, Bernardini et al. 2005) \\
22 & (Maruyama, Arai et al. 2001) \\
23 & (Reijn, Rikkert et al. 2007) \\
24 & (Mollenhauer, Bibl et al. 2006) \\
25 & (Sjogren, Davidsson et al. 2002) \\
26 & (Maddalena, Papassotiropoulos et al. 2003) \\
27 & (Nagga, Gottfries et al. 2002) \\
28 & (Riemenschneider, Schmolke et al. 2000) \\
29 & (Zetterberg, Andreasen et al. 2004) \\
30 & (Ibach, Binder et al. 2006) \\
31 & (Lee, Blennow et al. 2008) \\
32 & (Mulder, Schoonenboom et al. 2002) \\
33 & (Hulstaert, Blennow et al. 1999) \\
34 & (Olsson, Hoglund et al. 2003) \\
35 & (Prince, Zetterberg et al. 2004) \\
36 & (Andreasen, Minthon et al. 2001) \\
37 & (Hampel, Teipel et al. 2004) \\
38 & (Vanderstichele, Van Kerschaver et al. 2000) \\
39 & (Andreasen, Minthon et al. 1999) \\
\hline 0 & (Iqbal, Flory et al. 2005) \\
(Briani, Ruggero et al. 2002) \\
\hline
\end{tabular}

\section{References}

Andreasen N, Minthon L, et al. "Evaluation of CSF-tau and CSF-Abeta42 as diagnostic markers for Alzheimer disease in clinical practice." Arch Neurol 2001;58(3):373-9.

Andreasen N, Minthon L, et al. "Cerebrospinal fluid tau and Abeta42 as predictors of development of Alzheimer's disease in patients with mild cognitive impairment." Neurosci Lett 1999;273(1):5-8.

Brew BJ, Pemberton L, et al. "CSF amyloid beta 42 and tau levels correlate with AIDS dementia complex.” Neurology 2005;65(9):1490-2.

Briani C, Ruggero S, et al. "Combined analysis of CSF betaA42 peptide and tau protein and serum antibodies to glycosaminoglycans in Alzheimer's disease: preliminary data." J Neural Transm 2002;109(3):393-8.

Gomez-Tortosa E, Gonzalo I, et al. "Cerebrospinal fluid markers in dementia with lewy bodies compared with Alzheimer disease." Arch Neurol 2003; 60(9):1218-22.

Hampel H, Teipel SJ, et al. "Value of CSF beta-amyloid1-42 and tau as predictors of Alzheimer's disease in patients with mild cognitive impairment." Mol Psychiatry 2004;9(7):705-10.
Hulstaert F, Blennow K, et al. "Improved discrimination of AD patients using beta-amyloid(1-42) and tau levels in CSF." Neurology 1999; 52(8): 1555-62.

Ibach B, Binder H, et al. "Cerebrospinal fluid tau and beta-amyloid in Alzheimer patients, disease controls and an age-matched random sample." Neurobiol Aging 2006;27(9):1202-11.

Iqbal K, Flory M, et al. "Subgroups of Alzheimer's disease based on cerebrospinal fluid molecular markers." Ann Neurol 2005;58(5):748-57.

Ivanoiu A, Sindic CJ. "Cerebrospinal fluid TAU protein and amyloid beta42 in mild cognitive impairment: prediction of progression to Alzheimer's disease and correlation with the neuropsychological examination." Neurocase 2005;11(1):32-9.

Jia JP, Meng R, et al. "Cerebrospinal fluid tau, Abeta1-42 and inflammatory cytokines in patients with Alzheimer's disease and vascular dementia." Neurosci Lett 2005;383(1-2):12-6.

Kanemaru K, Kameda N, et al. "Decreased CSF amyloid beta42 and normal tau levels in dementia with Lewy bodies." Neurology 2000;54(9):1875-6. Kapaki E, Kilidireas K, et al. "Highly increased CSF tau protein and decreased beta-amyloid (1-42) in sporadic CJD: a discrimination from Alzheimer's disease?" J Neurol Neurosurg Psychiatry 2001;71(3):401-3.

Kapaki E, Paraskevas GP, et al. "CSF tau protein and beta-amyloid (1-42) in Alzheimer's disease diagnosis: discrimination from normal ageing and other dementias in the Greek population." Eur J Neurol 2003;10(2):119-28.

Lee JM, Blennow K, et al. "The brain injury biomarker VLP-1 is increased in the cerebrospinal fluid of Alzheimer disease patients." Clin Chem 2008; 54(10): 1617-23.

Maddalena A, Papassotiropoulos A, et al. "Biochemical diagnosis of Alzheimer disease by measuring the cerebrospinal fluid ratio of phosphorylated tau protein to beta-amyloid peptide42.” Arch Neurol 2003;60(9):1202-6.

Maruyama M, Arai H, et al. "Cerebrospinal fluid amyloid beta(1-42) levels in the mild cognitive impairment stage of Alzheimer's disease." Exp Neurol 2001;172(2):433-6.

Mollenhauer B, Bibl M, et al. "Total tau protein, phosphorylated tau (181p) protein, beta-amyloid(1-42), and beta-amyloid(1-40) in cerebrospinal fluid of patients with dementia with Lewy bodies." Clin Chem Lab Med 2006; 44(2):192-5.

Mollenhauer B, Cepek L, et al. "Tau protein, Abeta42 and S-100B protein in cerebrospinal fluid of patients with dementia with Lewy bodies." Dement Geriatr Cogn Disord 2005;19(2-3):164-70.

Mulder C, Schoonenboom SN, et al. "CSF markers related to pathogenetic mechanisms in Alzheimer's disease." J Neural Transm 2002; 109(12):1491-8.

Nagga K, Gottfries J, et al. "Cerebrospinal fluid phospho-tau, total tau and beta-amyloid(1-42) in the differentiation between Alzheimer's disease and vascular dementia." Dement Geriatr Cogn Disord 2002;14(4):183-90.

Noguchi M, Yoshita M, et al. "Decreased beta-amyloid peptide42 in cerebrospinal fluid of patients with progressive supranuclear palsy and corticobasal degeneration." J Neurol Sci 2005;237(1-2):61-5.

Olsson A, Hoglund K, et al. "Measurement of alpha- and beta-secretase cleaved amyloid precursor protein in cerebrospinal fluid from Alzheimer patients." Exp Neurol 2003;183(1):74-80.

Otto M, Esselmann H, et al. "Decreased beta-amyloid1-42 in cerebrospinal fluid of patients with Creutzfeldt-Jakob disease." Neurology 2000; 54(5):1099-102.

Pijnenburg YA, Schoonenboom NS, et al. "CSF tau and Abeta42 are not useful in the diagnosis of frontotemporal lobar degeneration." Neurology 2004; 62(9): 1649.

Prince JA, Zetterberg H, et al. "APOE epsilon4 allele is associated with reduced cerebrospinal fluid levels of Abeta42." Neurology 2004; 62(11):2116-8.

Reijn TS, Rikkert MO, et al. "Diagnostic accuracy of ELISA and xMAP technology for analysis of amyloid beta(42) and tau proteins." Clin Chem 2007;53(5):859-65.

Riemenschneider M, Schmolke M, et al. "Cerebrospinal beta-amyloid (1-42) in early Alzheimer's disease: association with apolipoprotein E genotype and cognitive decline." Neurosci Lett 2000;284(1-2):85-8. 
Riemenschneider M, Wagenpfeil S, et al. "Tau and Abeta42 protein in CSF of patients with frontotemporal degeneration." Neurology 2002; 58(11):1622-8.

Rosler N, Wichart I, et al. "Clinical significance of neurobiochemical profiles in the lumbar cerebrospinal fluid of Alzheimer's disease patients." $\mathrm{J}$ Neural Transm 2001;108(2):231-46.

Rosso SM, van Herpen E, et al. "Total tau and phosphorylated tau 181 levels in the cerebrospinal fluid of patients with frontotemporal dementia due to P301L and G272V tau mutations." Arch Neurol 2003;60(9):1209-13.

Schoonenboom NS, Pijnenburg YA, et al. "Amyloid beta(1-42) and phosphorylated tau in CSF as markers for early-onset Alzheimer disease." Neurology 2004;62(9):1580-4.

Sjogren M, Davidsson P, et al. "The cerebrospinal fluid levels of tau, growthassociated protein-43 and soluble amyloid precursor protein correlate in Alzheimer's disease, reflecting a common pathophysiological process." Dement Geriatr Cogn Disord 2001;12(4):257-64.

Sjogren M, Davidsson P, et al. "Decreased CSF-beta-amyloid 42 in Alzheimer's disease and amyotrophic lateral sclerosis may reflect mismetabolism of beta-amyloid induced by disparate mechanisms." Dement Geriatr Cogn Disord 2002;13(2):112-8.

Sjogren M, Minthon L, et al. "CSF levels of tau, beta-amyloid(1-42) and GAP-43 in frontotemporal dementia, other types of dementia and normal aging." J Neural Transm 2000;107(5):563-79.

Stefani A, Bernardini S, et al. AD with subcortical white matter lesions and vascular dementia: CSF markers for differential diagnosis. J Neurol Sci 2005;237(1-2):83-8.

Vanderstichele H, Van Kerschaver E, et al. "Standardization of measurement of beta-amyloid(1-42) in cerebrospinal fluid and plasma." Amyloid 2000;7(4):245-58.

Wallin AK, Blennow K, et al. "CSF biomarkers for Alzheimer's Disease: levels of beta-amyloid, tau, phosphorylated tau relate to clinical symptoms and survival." Dement Geriatr Cogn Disord 2006;21(3):131-8.

Zetterberg H, Andreasen N, et al. Neurosci Lett 2004;367(2):194-6.
Supplementary Table 2

Participating laboratories

\begin{tabular}{|c|c|c|c|}
\hline City & Country & $\begin{array}{l}\text { Lab type (Clinical/ } \\
\text { Research/Industry) }\end{array}$ & Principal investigator \\
\hline Aarhus & Denmark & Clinical & Aase Handberg \\
\hline Amsterdam & Netherlands & Clinical/Research & Marinus A. Blankenstein \\
\hline Athens & Greece & Clinical/Research & Elisabeth Kapaki \\
\hline Austin & USA & Industry & William Nowatzke \\
\hline Baltimore & USA & Clinical/Research & Marilyn Albert \\
\hline Barcelona & Spain & Clinical/Research & $\begin{array}{l}\text { Albert Lladó } \\
\text { José Luis Molinuevo }\end{array}$ \\
\hline Beerse & Belgium & Industry & Marc Mercken \\
\hline Bonn & Germany & Clinical/Research & Michael Heneka \\
\hline Brescia & Italy & Clinical/Research & Giovanni B. Frisoni \\
\hline Charlestown & USA & Research & Bradley T. Hyman \\
\hline Erlangen & Germany & Clinical/Research & Piotr Lewczuk \\
\hline Frankfurt & Germany & Clinical/Research & Harald Hampel \\
\hline Gent & Belgium & Industry & $\begin{array}{l}\text { Hugo Vanderstichele } \\
\text { Els Coart }\end{array}$ \\
\hline Grambach & Austria & Research/Industry & Manfred Windisch \\
\hline $\begin{array}{l}\text { Gothenburg/ } \\
\text { Mölndal }\end{array}$ & Sweden & Clinical/Research & Kaj Blennow \\
\hline Göttingen & Germany & Clinical/Research & Annette Spreer \\
\hline Heidelberg & Germany & Clinical/Research & Johannes Schröder \\
\hline Innsbruck & Austria & Clinical/Research & Christian Humpel \\
\hline Kuopio & Finland & Clinical/Research & Hilkka Soininen \\
\hline La Jolla & USA & Research & $\begin{array}{l}\text { Robert Rissman } \\
\text { Douglas Galasko }\end{array}$ \\
\hline Melbourne & Australia & Clinical/Research & Colin Masters \\
\hline Milan & Italy & Clinical/Research & Daniela Galimberti \\
\hline Nijmegen & Netherlands & Clinical/Research & Marcel Verbeek \\
\hline Oslo & Norway & Clinical/Research & Anders Skinningsrud \\
\hline Perth & Australia & Clinical/Research & Ralph Martins \\
\hline Perugia & Italy & Clinical/Research & Lucilla Parnetti \\
\hline Philadelphia & USA & Clinical/Research & $\begin{array}{l}\text { Leslie M. Shaw } \\
\text { John Q Trojanowski }\end{array}$ \\
\hline Rochester & USA & Research & Ronald C. Petersen \\
\hline Rome & Italy & Clinical/Research & Alessandro Stefani \\
\hline $\begin{array}{l}\text { South San } \\
\text { Fransisco }\end{array}$ & USA & Industry & Daniel Kidd \\
\hline Sao Paolo & Brazil & Clinical/Research & Wagner Gattaz \\
\hline Seattle & USA & Research & Thomas Montine \\
\hline Sendai & Japan & Clinical & Hiroyuki Arai \\
\hline St. Louis & USA & Clinical/Research & $\begin{array}{l}\text { Anne M. Fagan } \\
\text { David M. Holtzman }\end{array}$ \\
\hline Staten Island & USA & Research & Khalid Iqbal \\
\hline Stockholm & Sweden & Clinical/Research & Gunilla Dahlfors \\
\hline Szeged & Hungary & Clinical/Research & Laszlo Vecsei \\
\hline Tübingen & Germany & Clinical/Research & Mathias Jucker \\
\hline Ulm & Germany & Clinical/Research & Markus Otto \\
\hline Worcester & USA & Industry & Dev Batish \\
\hline
\end{tabular}


Supplementary Table 3

Factors contributing to the total variability ${ }^{\mathrm{a}}$

\begin{tabular}{|c|c|c|}
\hline Technology & Biomarker & $\begin{array}{l}\text { Ranking of factors contributing } \\
\text { to the total variability }{ }^{\mathrm{b}}\end{array}$ \\
\hline \multirow[t]{8}{*}{ ELISA } & \multirow[t]{2}{*}{$\mathrm{A} \beta 42$} & $\begin{array}{l}\text { 1. Between-laboratory and within-laboratory } \\
\text { (equal contributions) }\end{array}$ \\
\hline & & 2. Between-lot \\
\hline & \multirow[t]{3}{*}{ T-tau } & 1. Within-laboratory \\
\hline & & 2. Between-laboratory \\
\hline & & 3. Between-lot \\
\hline & \multirow[t]{3}{*}{ P-tau } & 1. Between-laboratory \\
\hline & & 2. Within-laboratory \\
\hline & & 3. Between-lot \\
\hline \multirow{9}{*}{ Luminex } & \multirow{3}{*}{$\mathrm{A} \beta 42$} & 1. Between-laboratory \\
\hline & & 2. Between-lot \\
\hline & & 3. Within-laboratory \\
\hline & \multirow[t]{3}{*}{ T-tau } & 1. Within-laboratory \\
\hline & & 2. Between-laboratory \\
\hline & & 3. Between-lot \\
\hline & \multirow[t]{3}{*}{ P-tau } & 1. Within-laboratory \\
\hline & & 2. Between-laboratory \\
\hline & & 3. Between-lot \\
\hline
\end{tabular}

\footnotetext{
${ }^{\text {a }}$ Variability estimated using variance component analysis.

b 1 indicates the most contribution and 3 the least contribution to the total variability. The ranking should be interpreted with caution due to few data points in the analysis.
} 

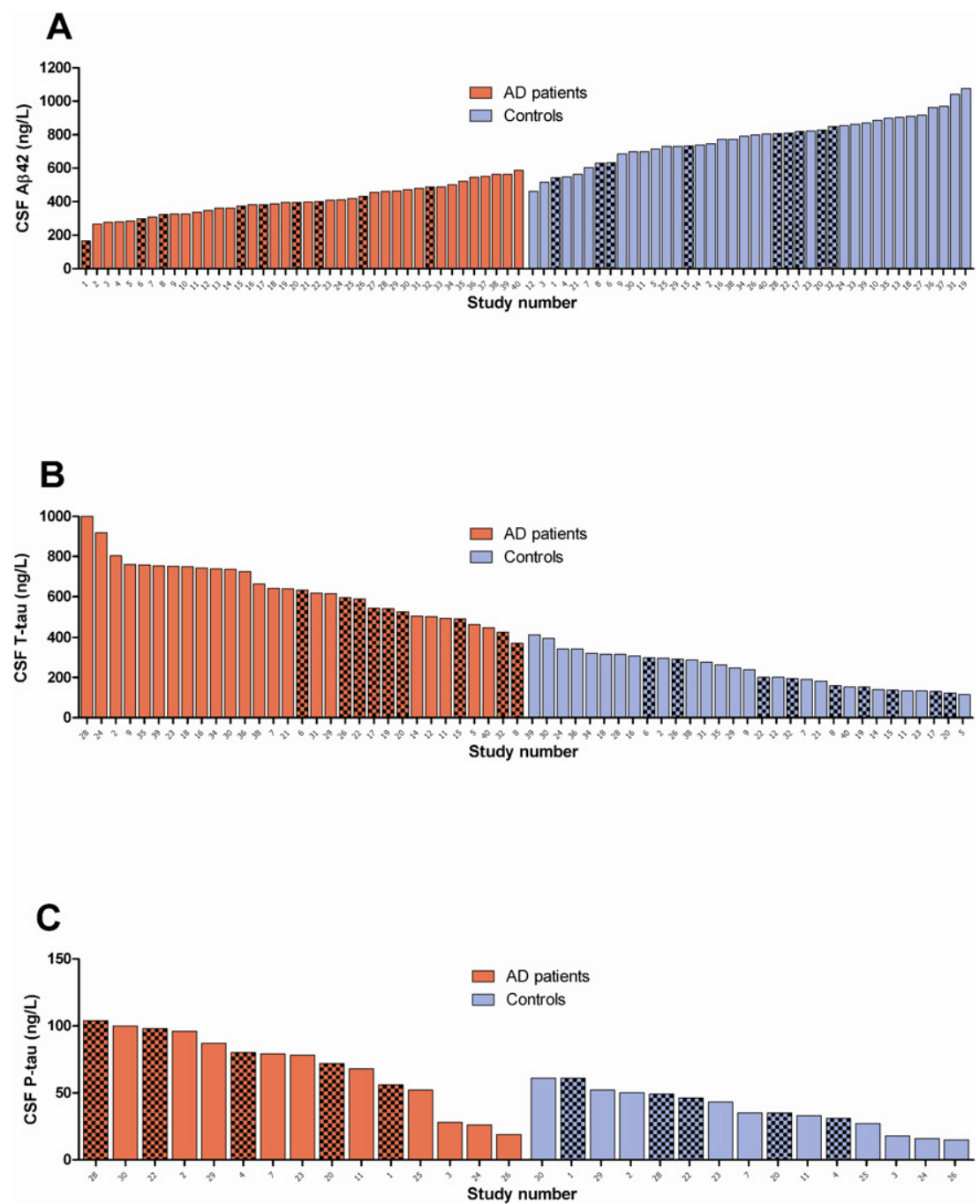

Supplementary Fig. 1. Mean and median levels of CSF A(1-42) (A), CSF T-tau (B) and CSF-P-tau181 (C) in 40 studies using the INNOTEST ${ }^{\circledR}$ ELISA (Innogenetics, Ghent, Belgium). The studies included approximately $2700 \mathrm{AD}$ patients and 1400 controls. Studies reporting median levels are indicated by checked boxes. See supplementary table 1 for references to studies. The aim of this figure is to show the variation between studies, not to give a complete review of all CSF AD biomarker studies. 

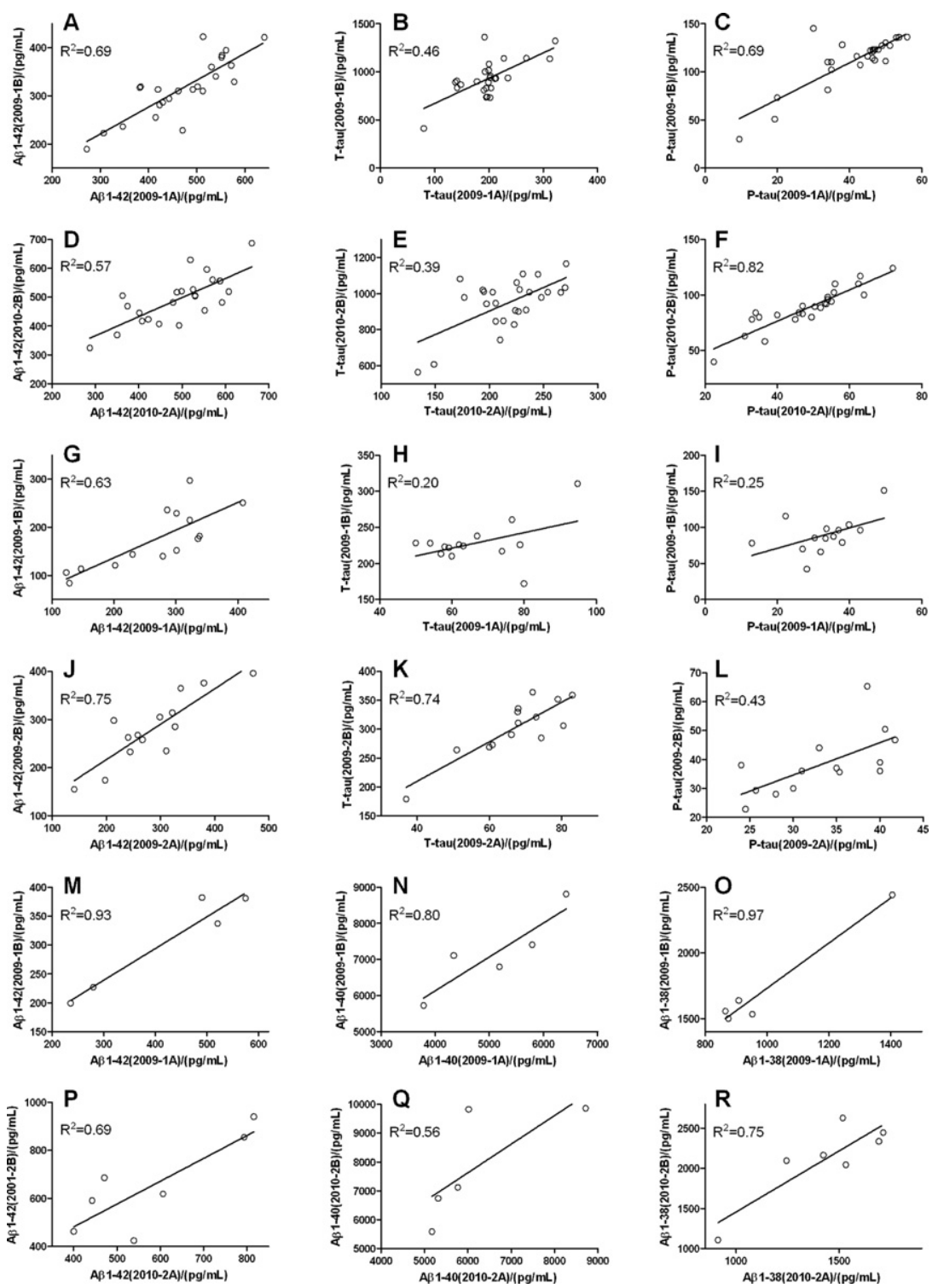

Supplementary Fig. 2. Correlations between sample A and B for ELISA (round 1, A-C; round 2, D-F), XMAP® (round 1, G-I; round 2, J-L) and MSD ${ }^{(\text {round }}$ 1, M-O; round 2, P-R). 

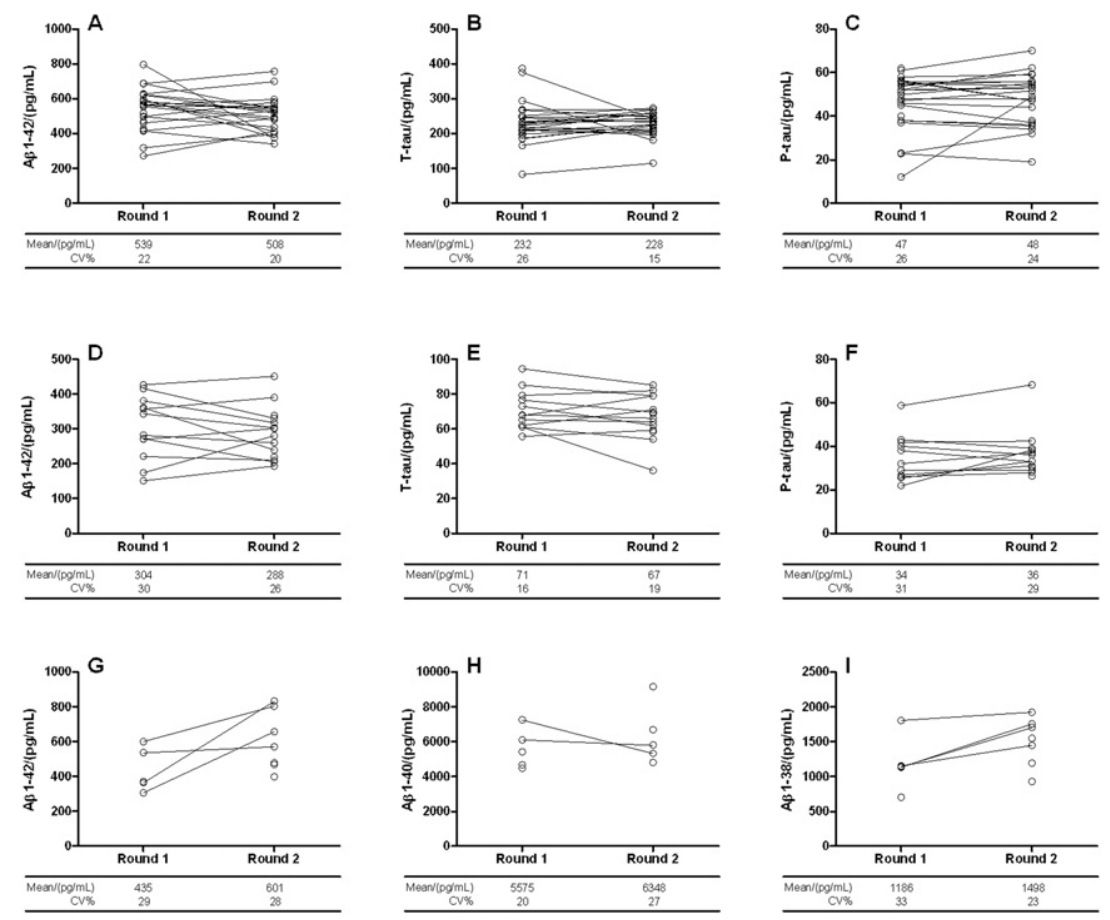

Supplementary Fig. 3. Results for QC-L samples measured at the first and the second round. ELISA results in panels A-C, xMAP ${ }^{R}$ results in panels D-F and MSD ${ }^{\circledR}$ results in panels G-I. 